\title{
The Relationship Between Intrahospital Mortality and P-Wave Dispersion in COVID-19 Patients
}

\author{
- Ugur Kucuk, • Hasan Ata Bolayir* \\ Canakkale Onsekiz Mart University Faculty of Medicine, Department of Cardiology, Canakkale, Turkey \\ *Firat University Faculty of Medicine, Department of Cardiology, Elazig, Turkey
}

Abstract

\begin{abstract}
Aim: P-wave dispersion (PWD) is a noninvasive electrocardiographic (ECG) marker of atrial remodeling. Inflammations are likely to cause atrial remodeling. This study aims to determine the relationship between PWD and intrahospital mortality in Coronavirus disease-2019 (COVID-19) patients.

Methods: One hundred eighty-nine patients who tested positive for polymerase chain reaction for a diagnosis of COVID-19 between March 2020 and January 2021 were included in the cross-sectional study. PWD was calculated from the pre-treatment ECG of all patients at the time of hospitalization.

Results: Mean PWD values were numerically and statistically significant in the group who died in hospital compared to the group discharged after recovery $(46.37 \pm 19.00 \mathrm{~ms}$ vs. $31.86 \pm 11.08 \mathrm{~ms}, \mathrm{p}<0.001)$. Regardless of gender, regression analysis found an independent relationship between PWD values and mortality in COVID-19 patients. In the receiver operating characteristic curve analysis, PWD values above $34 \mathrm{~ms}$ had 73\% sensitivity and 69\% specificity in predicting all-cause mortality in COVID-19 patients (area under the curve: 0.737 , confidence interval: 0.666-0.808, $p<0.001$ ).
\end{abstract}

Conclusions: PWD was associated with in-hospital mortality in COVID-19 patients. The findings of this study demonstrate that the PWD values calculated at the time of hospitalization can be helpful in determining the prognosis of COVID-19 patients.

Keywords: P-wave dispersion, SARS-CoV-2, COVID-19, electrocardiography, mortality

\section{Introduction}

Despite our increasing experience with Coronavirus disease-2019 (COVID-19) and the diversity of medical treatment options, its mortality remains high (1). As the number of cases increases, cardiovascular diseases are increasingly reported (2). Multiorgan involvement occurs as a result of both the direct effect of the virus and the cytokine storm. Decreased cell perfusion, hypoxia, and increased inflammatory responses during the course of the disease are the main mechanism of many clinical conditions, and as the clinical condition worsens, there are serious difficulties with the accompanying differential diagnoses (3).

Electrocardiography (ECG) has been confirmed to be useful in many clinical situations outside cardiology practice. Each wave seen on the ECG strip (such as P, QRS, and T-wave) gives clues to the clinician about the patient's clinical situation (4).

The P-wave is an indicator of atrial transmission and reflects the subclinical conditions (e.g. fibrosis and atrial inflammation) of the atria (5). In the Framingham Heart Study, in which P-wave duration, amplitude, and length were examined, prolongation of the PR interval was shown to be associated with increased mortality and atrial fibrillation (6). According to what we know from previous studies, myocardial damage can occur as a result of the direct effect of the viral pathogen causing the infection or systemic inflammation (7). To the best of our knowledge, although PWD has been revealed to be associated with atrial fibrillation in COVID-19 patients, its relationship with mortality has not been examined.

Address for Correspondence: Ugur Kucuk, Canakkale Onsekiz Mart University Faculty of

Medicine, Department of Cardiology, Canakkale, Turkey

E-mail: drugurkucuk@hotmail.com ORCID: orcid.org/0000-0003-4669-7387

Received: 02.06.2021 Accepted: 14.10.2021

Copyright 2021 by The Medical Bulletin of istanbul Haseki Training and Research Hospital The Medical Bulletin of Haseki published by Galenos Yayınevi. 
The aim of this study was to analyze the usability of P-wave dispersion in predicting in-hospital mortality in patients diagnosed with COVID-19.

\section{Methods}

\section{Patients and Study Design}

Before the study, approval was obtained from the COVID-19 Science Committee of the Ministry of Health (reference number: 2021-03-11T13_34_23) and our Canakkale Onsekiz Mart University's Ethics Committee (date: 31.03.2021 decision no: 2011-KAEK27/2021-E.2100040583). Due to the design of the study, informed consent was not received from the participants. This study was carried out in accordance with the Declaration of Helsinki.

This study is a single-center cross-sectional study and was conducted in a tertiary health center between 15 March 2020 and 1 January 2021. Patients newly diagnosed with a positive polymerase chain reaction test were included in the study for the diagnosis of COVID-19. The PWD of the patients was calculated from the ECG taken before starting treatment. Patients were divided into two groups: Group 1, those who lost their lives in the hospital, and group 2, those who were discharged after recovery.

Demographic data, laboratory results and cardiac risk factors were obtained from electronic medical records and recorded for both groups.

This study did not include those with active infections other than COVID-19, those with acute cerebrovascular disease, severe renal and liver failure, those with a permanent pacemaker and pace rhythm, those with any kind of branch blocks, those with malignant disease, those who took antiarrhythmic drugs that can cause PR prolongation, those with application rhythm atrial fibrillation and patients under 18 years of age.

\section{Definitions}

Hypertension was defined as systolic blood pressure above $140 \mathrm{mmHg}$ and diastolic blood pressure above 90 $\mathrm{mmHg}$ or the use of antihypertensive drugs. Diabetes mellitus was defined as fasting blood glucose above 126 $\mathrm{mg} / \mathrm{dL}$ or the use of antidiabetic medication. Smoking was identified as the use of cigarettes for more than the previous six months.

The ECGs (Fukuda Denshi, Tokyo, Japan) of all the patients included in the study, taken in the supine position with 12 leads, $25 \mathrm{~mm} / \mathrm{s}$ paper speed and $1 \mathrm{mV} / \mathrm{cm}$ width, were taken during hospitalization and recorded in the hospital's electronic database. The ECGs were evaluated in a computer environment and enlarged when necessary during the measurement.
In evaluating ECGs in the sinus rhythm, an isoelectric line was determined in which all patients initially accepted the start and end of the P-wave. Two R-R distances were used to calculate heart rate. Then the $P$ wave with the longest duration in 12 derivations was considered the P-maximum (Pmax) and the P-wave with the shortest duration was considered the P-minimum (Pmin). The difference between Pmax and Pmin was considered to be the PWD (8).

The PR interval was defined as the length between the beginning of the P wave and the QRS complex; the P-wave duration (PWD) was defined as the length between the start and end of the P-wave. The QRS complex, on the other hand, was defined as the end point of the $S$ wave from the end point of the PR. All ECGs were evaluated twice on two different days by two different specialists who did not know the clinic of the independent patients. Interclass and intraclass correlations achieved reliabilities of $96 \%$ and $94 \%$ respectively.

\section{Statistical Analysis}

The Kolmogorov-Smirnov test was used to evaluate the distribution of continuous variables. Continuous variables obtained as a result of the analysis were expressed as mean \pm standard deviation, whereas the data that did not conform to normal distribution are expressed as median and interquartile range. Categorical variables were expressed as percentages and numbers. The t-test and Mann-Whitney $U$ test were used to compare parameters that were compatible with normal distribution and those that were not. The chi-square test was used when comparing the odds ratios of categorical variables. The relationship between PWD and all-cause mortality was shown in separate box-plot graphs. Pearson correlation analysis was used for correlation between PWD values and demographic and laboratory variables. The effects of variables such as age, DM, HT, Platelet, Max $P$ and Min $P$ wave duration, PR interval and PWD on predicting intrahospital mortality in patients with COVID-19 were evaluated separately for males and females with backward stepwise regression. ROC analysis was performed for the usability of PWD to predict mortality and the results are shown on an ROC curve. P-values below 0.05 were considered statistically significant. Statistical data were obtained using the SPSS 19.0 (SPSS Inc, Chicago, IL, USA) application.

$\mathrm{G}^{*}$ power analysis (effect size 0.50 , alpha error: 0.05 and to have $80 \%$ power) was used to calculate the results were calculated for 128 patients (64 patients in group 1 and 64 patients in group 2), and a total of 189 patients (94 in group 1 and 95 in group 2) was included in the study. 


\section{Results}

One hundred-eighty-nine people, comprising 80 female and 109 male patients, were included in the study. The patients were divided into two groups. Those who lost their lives in the hospital formed group 1, while those who were discharged after recovery made up group 2 . The mean age of the patients in group 1 was $73.5 \pm 12.4$ years and it consisted of 51 male and 43 female patients. The mean age of the patients in group 2 was $73.9 \pm 13.5$ and it consisted of 58 male and 37 female patients. C-reaktif protein (CRP), CRP/albumin ratio, serum ferritin, D-dimer, and Hs-TnT values were higher in the group 1 patients, i.e. those who died in hospital. There was no statistically significant difference between the groups in terms of fever and basal oxygen saturation at the first admission $(p=0.329$ and $p=0.111$, respectively) (Table 1$)$.

\begin{tabular}{|c|c|c|c|}
\hline \multirow[b]{2}{*}{ Clinical characteristics } & \multicolumn{2}{|l|}{ Patients } & \multirow[b]{2}{*}{ p } \\
\hline & $\begin{array}{l}\text { Non-survivors } \\
(n=94)\end{array}$ & $\begin{array}{l}\text { Survivors } \\
(n=95)\end{array}$ & \\
\hline $\begin{array}{l}\text { Age, years } \\
\text { Mean } \pm \text { SD } \\
\text { Gender, n (\%) } \\
\text { Males } \\
\text { Females } \\
\text { Smoking, n (\%) } \\
\text { Co-morbidities, n (\%) }\end{array}$ & $\begin{array}{l}73.5 \pm 12.4 \\
51(54) \\
43(45.7) \\
22(23)\end{array}$ & $\begin{array}{l}73.7 \pm 13.5 \\
58(61) \\
37(39) \\
14(15)\end{array}$ & $\begin{array}{l}0.901 \\
0.503 \\
0.502 \\
0.129\end{array}$ \\
\hline DM & $20(20)$ & $21(22)$ & 0.377 \\
\hline $\begin{array}{l}\text { HTN } \\
\text { Fever, n (\%) } \\
\text { Basal oxygen saturation, \% }\end{array}$ & $\begin{array}{l}37(39) \\
35(37) \\
91(89-93) \\
\end{array}$ & $\begin{array}{l}30(32) \\
42(44) \\
92(90-93)\end{array}$ & $\begin{array}{l}0.263 \\
0.329 \\
0.111 \\
\end{array}$ \\
\hline $\begin{array}{l}\text { Laboratory data, mean } \pm \mathrm{SD} \\
\text { Glucose, } \mathrm{mg} / \mathrm{dL} \\
\text { Creatinine, } \mathrm{mg} / \mathrm{dL} \\
\text { White blood cell, }\left(\times 10^{3} \mathrm{\mu L}\right) \\
\text { Hemoglobin, } \mathrm{g} / \mathrm{dL} \\
\text { Platelet, }\left(\times 10^{3} \mathrm{\mu L}\right) \\
\text { Neutrophil, }\left(\times 10^{3} / \mathrm{L}\right) \\
\text { Lymphocyte }\left(\times 10^{3} / \mathrm{L}\right) \\
\mathrm{CRP}, \mathrm{mg} / \mathrm{dL} \\
\text { Total protein, }(\mathrm{g} / \mathrm{dL}) \\
\text { Albumin, (g/dL) } \\
\text { Procalsitonin } \\
\text { CRP/albumin raito } \\
\text { Laboratory data, median } \\
\text { (per 25-75) } \\
\text { Fibrinogen } \\
\text { Serum ferritin } \\
\text { D-dimer, ng/Ml } \\
\text { Hs-TnT, ng/L } \\
\text { Medications, } \mathrm{n}(\%) \\
\text { Hydroxychloroquine } \\
\text { Oseltamivir } \\
\text { Azithromycin } \\
\text { Favipiravir }\end{array}$ & $\begin{array}{l}165.61 \pm 71.44 \\
1.01 \pm 0.29 \\
12.53 \pm 4.48 \\
11.89 \pm 2.16 \\
218.26 \pm 85.19 \\
7.84 \pm 5.14 \\
0.89 \pm 0.99 \\
12.78 \pm 10.92 \\
6.06 \pm 0.94 \\
3.01 \pm 0.73 \\
6.38 \pm 17.08 \\
4.58 \pm 4.10 \\
\\
646(505-860) \\
520(38-232) \\
1512(652-2592) \\
103(27-211) \\
\\
51(54) \\
32(34) \\
35(37) \\
28(30)\end{array}$ & $\begin{array}{l}149.40 \pm 56.19 \\
0.96 \pm 0.28 \\
12.63 \pm 4.40 \\
12.26 \pm 2.16 \\
244.58 \pm 77.58 \\
6.98 \pm 5.43 \\
0.67 \pm 0.78 \\
6.59 \pm 10.92 \\
6.21 \pm 0.91 \\
3.10 \pm 0.77 \\
8.26 \pm 12.66 \\
2.33 \pm 4.10\end{array}$ & $\begin{array}{l}0.085 \\
0.290 \\
0.886 \\
0.242 \\
0.028^{a} \\
0.265 \\
0.089 \\
<0.001^{a} \\
0.252 \\
0.398 \\
0.393 \\
<0.001^{a}\end{array}$ \\
\hline
\end{tabular}

SD: Standard deviations, DM: Diabetes mellitus, HTN: Hypertension, CRP: C-reactive protein, Hs-TnT: high-sensitivity troponin T, $\alpha$ : T-test, $\beta$ : Mann-Whitney U-test. Blood parameters may differ between groups in COVID-19 patients
While a positive correlation was observed with $P W D$, $\operatorname{CRP}(r=0.145, P=0.047)$ and $C R P / a l b u m i n$ ratio $(r=0.162$, $\mathrm{P}=0.026)$ in the Pearson correlation analysis, a negative correlation was observed between platelets ( $r=-0.147$, $\mathrm{P}=0.044$ ) and PWD was observed (Table 2).

In electrocardiographic examinations, the PR interval $(p=0.025), Q R S$ width $(p<0.001), P W D$ viewed from D2 derivation $(p=0.015)$, max P-wave duration $(p<0.001)$ and PWD $(p<0.001)$ variables were numerically and statistically significant in the group that died in the hospital compared to the group that was discharged after full recovery (Table 3).

As a result of the backward stepwise regression analysis, while the Pmax wave duration $(p=0.021)$, PR interval $(p=0.048)$, PWD $(p=0.024)$ and PWD $(p=0.004)$ in male patients with COVID-19 diagnosis, platelet in female patients $(p=0.012)$ max PWD $(p=0.003)$ and PWD $(p<0.001)$ were independent predictors of mortality (Table 4 ).

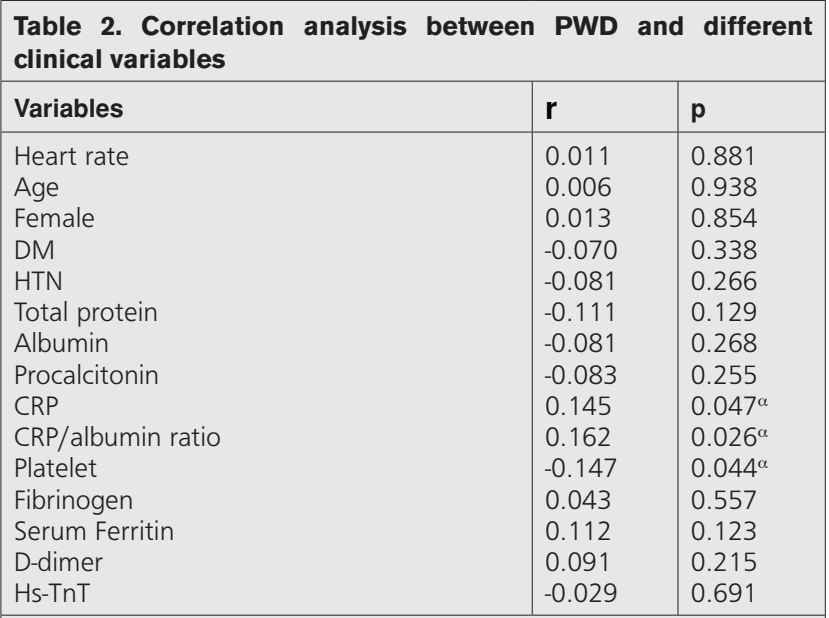

PWD: P-wave dispersion, DM: Diabetes mellitus, HTN: Hypertension, CRP: C-reactive protein, Hs-TnT: high-sensitivity troponin $\mathrm{T}, \alpha$ : Pearson correlation analysis. PWD is correlated with CRP/albumin ratio which is one of the infection parameters

Table 3. Electrocardiographic characteristics of COVID-19 patients

\begin{tabular}{|c|c|c|c|}
\hline \multirow[b]{2}{*}{ Parameters } & \multicolumn{2}{|c|}{ Patients } & \multirow[b]{2}{*}{$\mathbf{p}$} \\
\hline & $\begin{array}{l}\text { Non- } \\
\text { survivors }\end{array}$ & Survivors & \\
\hline $\begin{array}{l}\text { Heart rate (bpm) } \\
\text { PR interval (ms) } \\
\text { QRS width (ms) } \\
\text { P wave duration, lead II, ms } \\
\text { Max P-wave duration (ms) } \\
\text { Min P-wave duration (ms) } \\
\text { PWD (ms) } \\
\text { PWD } \geq 34 \text { ms, } n(\%)\end{array}$ & $\begin{array}{l}88.77 \pm 15.85 \\
137.27 \pm 37.44 \\
107.15 \pm 21.38 \\
127.98 \pm 40.60 \\
98.63 \pm 24.01 \\
52.26 \pm 15.18 \\
46.37 \pm 19.00 \\
69(73.4)\end{array}$ & $\begin{array}{l}92.65 \pm 18.68 \\
122.63 \pm 50.53 \\
93.05 \pm 22.22 \\
111.63 \pm 50.53 \\
82.06 \pm 13.32 \\
50.31 \pm 11.23 \\
31.86 \pm 11.08 \\
30(32)\end{array}$ & $\begin{array}{l}0.125 \\
0.025^{\alpha} \\
<0.001^{\alpha} \\
0.015^{\alpha} \\
<0.001^{\alpha} \\
0.316 \\
<0.001^{\alpha} \\
<0.001^{\beta}\end{array}$ \\
\hline \multicolumn{4}{|c|}{$\begin{array}{l}\text { PWD: P-wave dispersion } \\
\alpha: \text {-test, } \beta \text { : Chi-square test, PWD is significantly higher in COVID-19 patients who } \\
\text { died in hospital }\end{array}$} \\
\hline
\end{tabular}


As shown in Figure 1, the mean PWD values were numerically and statistically significant in non-survivors compared to survivors $(46.37 \pm 19.00 \mathrm{~ms}$ v31.86 \pm 11.08 $m s, p<0.001)$.

PWD values over $34 \mathrm{~ms}$ in the ROC curve analysis had $73 \%$ sensitivity in estimating all-cause mortality in the COVID-19 patients, and a 69\% specificity (area under curve: 0.737, confidence interval: 0.666-0.808, $p<0.001$ ) (Figure 2). The distribution of patients with PWD $\geq 34 \mathrm{~ms}$ is shown in Figure 3.

\section{Discussion}

To our knowledge, our study is the first to show that PWD has been found to be a predictor of intrahospital mortality in COVID-19 patients. The main results of the study were that PWD values were higher on surface ECG in those COVID-19 patients who lost their lives. Another important result was that PWD was associated with allcause deaths in both females and male patients diagnosed with COVID-19.
Severe Acute Respiratory Syndrome-Coronavirus-2 (SARS-CoV-2) causes serious mortality and morbidity with its multisystemic organ involvement. COVID-19 has a poor prognosis despite new treatments and vaccines (9). Although laboratory parameters such as troponin, serum ferritin and D-dimer are predictors of a poor prognosis, the criteria for giving a poor prognosis are still not sufficient (10). Underlying diseases such as HT, DM, chronic kidney failure, and ischemic heart disease are common in those who die due to COVID-19 (11). Also, CRP elevation, hypoalbuminemia, and thrombopenia are markers of poor prognosis in COVID-19 patients (12). Although laboratory findings and additional underlying diseases indicate a poor prognosis, these are common results seen in many infectious cases and are not specific for a particular disease.

It is known that the cardiovascular system is retained either directly or indirectly due to SARS-CoV-2 (13). An ECG analysis by McCullough and colleagues showed that T-wave inversion and nonspecific repolarization

\section{Table 4. Regression analysis for PWD and clinical variables of males and females}

\begin{tabular}{|c|c|c|c|c|c|c|}
\hline \multirow[b]{2}{*}{ Parameters } & \multicolumn{3}{|c|}{ Males } & \multicolumn{3}{|c|}{ Females } \\
\hline & Exp & $95 \%$ & $\mathbf{p}$ & Exp & $95 \%$ & $\mathbf{p}$ \\
\hline $\begin{array}{l}\text { Age } \\
\text { DM } \\
\text { HTN } \\
\text { Platelet } \\
\text { Max P-wave duration } \\
\text { Min P-wave duration } \\
\text { PR interval } \\
\text { P-wave duration } \\
\text { PWD }\end{array}$ & $\begin{array}{l}0.983 \\
0.939 \\
0.455 \\
1.002 \\
0.964 \\
0.985 \\
0.992 \\
0.991 \\
0.960\end{array}$ & $\begin{array}{l}0.953-1.013 \\
0.384-2.296 \\
0.200-1.032 \\
0.997-1.006 \\
0.941-0.988 \\
0.959-1.012 \\
0.984-1.000 \\
0.983-0.999 \\
0.933-0.987\end{array}$ & $\begin{array}{l}0.256 \\
0.890 \\
0.060 \\
0.452 \\
0.003^{\alpha} \\
0.283 \\
0.048^{\alpha} \\
0.024^{\alpha} \\
0.004^{\alpha}\end{array}$ & $\begin{array}{l}1.033 \\
0.571 \\
1.286 \\
1.008 \\
0.911 \\
0.994 \\
0.993 \\
0.994 \\
0.877\end{array}$ & $\begin{array}{l}0.944-1.074 \\
0.208-1.568 \\
0.524-3.154 \\
1.002-1.014 \\
0.869-0.956 \\
0.958-1.031 \\
0.982-1.005 \\
0.982-1.006 \\
0.825-0.932\end{array}$ & $\begin{array}{l}0.098 \\
0.277 \\
0.583 \\
0.012^{\alpha} \\
<0.001^{\alpha} \\
0.741 \\
0.272 \\
0.319 \\
<0.001^{\alpha}\end{array}$ \\
\hline
\end{tabular}

DM: Diabetes mellitus, HTN: Hypertension, PWD: P-wave dispersion, ${ }^{\alpha}$ : Backward stepwise regression analysis, regardless of gender, increased PWD values are predictors of mortality in COVID-19 patients who died in the hospital

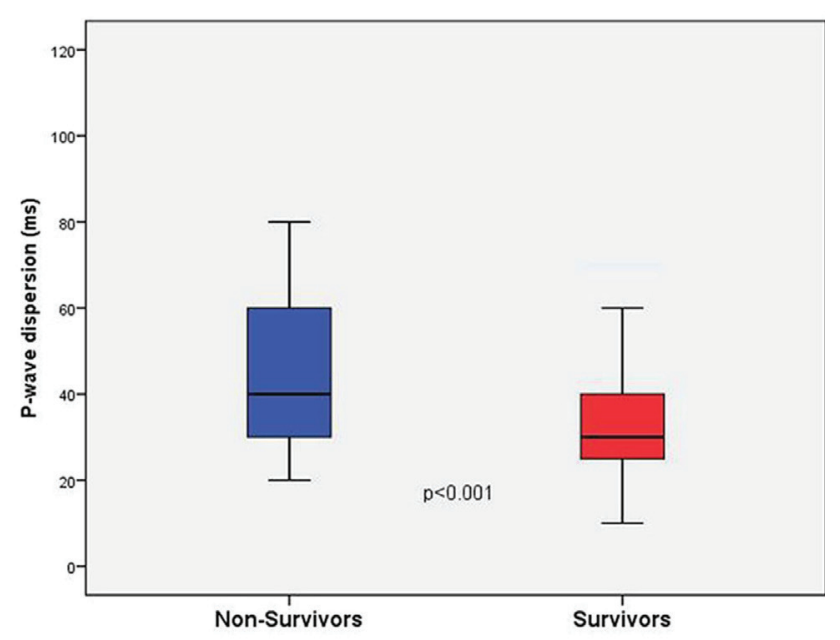

Figure 1. Comparison of PWD for COVID-19 non-survivors and survivors

PWD: P-wave dispersion, COVID-19: Coronavirus disaese-2019

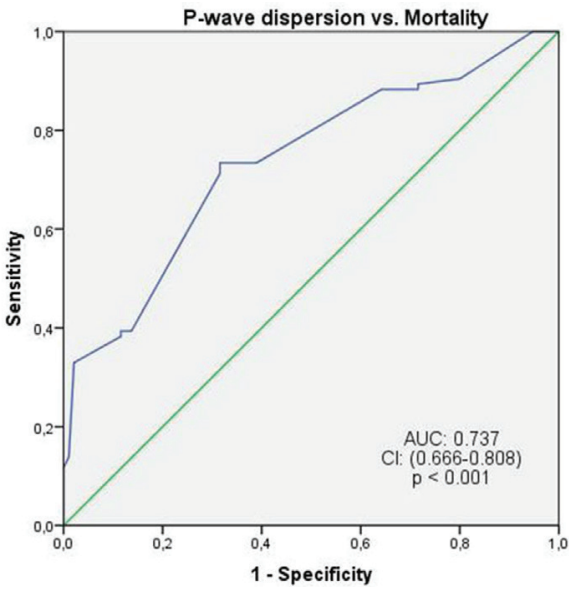

Figure 2. Receiver operating characteristic curve of PWD for predict in-hospital mortality in patients with COVID-19 disease PWD: P-wave dispersion, COVID-19: Coronavirus disaese-2019, $\mathrm{Cl}$ : Confidence interval, AUC: Area under the curve 


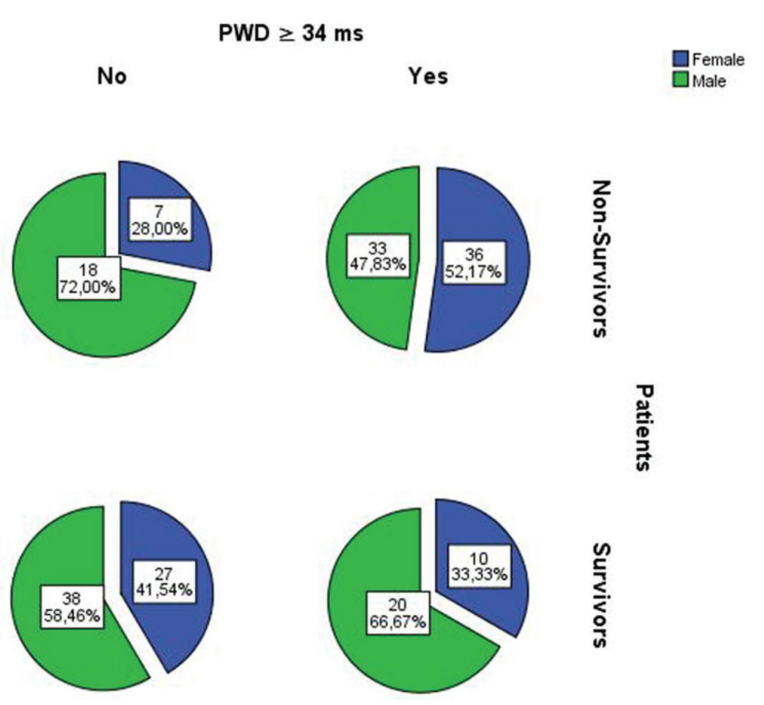

Figure 3. Distribution of patients with PWD $\geq 34$ ms between groups

PWD: P-wave dispersion

abnormalities were associated with increased mortality rates in COVID-19 patients (14). Despite this, the relationship of PWD to intrahospital mortality in COVID-19 patients has not been investigated.

PWD is an important indicator for atrial transmission and can be easily calculated from ECG samples. Prolonged periods are called interatrial blocks and have not been adequately investigated in clinical practice (15). Although the underlying cause is not certain, intercellular fibrotic changes have been pointed to as the reason. Although fibrotic changes were monitored as secondary to an increase in the left atrium diameter, in animal models prolonged PWD values have also been shown, regardless of left atrium diameters (16). In the current study of patients hospitalized with a diagnosis of COVID-19, PWD values were found to be both prolonged and associated with increased mortality in the group who died.

In cases of systemic inflammation, atrial remodeling causes delays in depolarization along with changes to membrane potential. These result in changes in the duration of the $P$ wave in the clinic (17). As seen in various infection tables for COVID-19, data such as increased CRP levels, neutrophilia and lymphopenia have been identified as markers indicating the severity of inflammation. It is known from previous studies that inflammation can have effects on ECG (18). In the current study, a positive correlation was observed between CRP values and PWD. Autopsy studies conducted in COVID-19 patients found that heart muscle cells were infiltrated and there was cardiomyocyte damage (19). Although atrial fibrosis can be demonstrated by biopsy and radiological methods, these methods are expensive and can be difficult to access. In the current research, as a result of the ROC curve analysis, PWD values of 34 and above had predictive values for mortality in COVID-19 patients, and it is possible to demonstrate this with a noninvasive method such as ECG.

\section{Study Limitations}

Although the current study obtained significant results, it has some limitations. First, this was a single-center study with a small number of patients. Second, since only the ECGs of the patients at the time of hospitalization were evaluated, we did not have information about the change in PWD during follow-up. Third, we did not have access to information about the left atrium diameter, since echocardiography could not be performed on most patients due to the risk of exposure to the infection. Despite these limitations, the study had strengths. Although our study was a single center and the number of patients was small, it had $80 \%$ power as a result of $\mathrm{G}^{*}$ power analysis. Additionally, our inter-observer and inter-observer measures showed minimal variation. PWD was still significantly higher in those who died in-hospital compared to those who were discharged after recovery. Therefore, the increase in PWD assessment will give the clinician an idea about the prognosis of patients with COVID-19 patients.

\section{Conclusions}

PWD can be calculated by easy and noninvasive methods. Increased PWD values correlate with inflammation indicators, suggesting that transmission in atrial tissue is affected secondary to inflammation. In addition, the current study shows that PWD can help in determining the prognosis of COVID-19 patients.

\section{Authorship Contributions}

Concept: U.K., H.A.B., Design: U.K., H.A.B., Data Collection or Processing: U.K., H.A.B., Analysis or Interpretation: U.K., H.A.B., Literature Search: U.K., H.A.B., Writing: U.K., H.A.B.

Conflict of Interest: No conflict of interest was declared by the authors.

Financial Disclosure: The authors declared that this study received no financial support.

\section{References}

1. Loomba RS, Aggarwal G, Aggarwal S, et al. Disparities in case frequency and mortality of coronavirus disease 2019 (COVID-19) among various states in the United States. Ann Med 2021;53:151-9.

2. Huang $C$, Wang $Y$, Li $X$, et al. Clinical features of patients infected with 2019 novel coronavirus in Wuhan, China. Lancet 2020;395:497-506. 
3. Degauque N, Haziot A, Brouard S, Mooney N. Endothelial cell, myeloid, and adaptive immune responses in SARS-CoV-2 infection. FASEB J 2021;35:e21577.

4. Pendell Meyers H, Bracey A, et al. Accuracy of OMI ECG findings versus STEMI criteria for diagnosis of acute coronary occlusion myocardial infarction. Int J Cardiol Heart Vasc 2021:33:100767.

5. Cha YM, Redfield MM, Shen WK, Gersh BJ. Atrial fibrillation and ventricular dysfunction: a vicious electromechanical cycle. Circulation 2004;109:2839-43.

6. Magnani JW, Mazzini MJ, Sullivan LM, Williamson M, Ellinor PT, Benjamin EJ. P-wave indices, distribution and quality control assessment (from the Framingham Heart Study). Ann Noninvasive Electrocardiol 2010;15:77-84.

7. Centurión OA, Scavenius KE, García LB, Torales JM, Miño LM. Potential Mechanisms of Cardiac Injury and Common Pathways of Inflammation in Patients With COVID-19. Crit Pathw Cardiol 2021;20:44-52.

8. Aytemir K, Ozer N, Atalar E, et al. P wave dispersion on 12lead electrocardiography in patients with paroxysmal atrial fibrillation. Pacing Clin Electrophysiol 2000;23:1109-12.

9. van Dam PMEL, Zelis $\mathrm{N}$, van Kuijk SMJ, et al. Performance of prediction models for short-term outcome in COVID-19 patients in the emergency department: a retrospective study. Ann Med 2021;53:402-9.

10. Huang I, Pranata R, Lim MA, Oehadian A, Alisjahbana B. C-reactive protein, procalcitonin, D-dimer, and ferritin in severe coronavirus disease-2019: a meta-analysis. Ther Adv Respir Dis 2020;14:1753466620937175.
11. Piroth L, Cottenet J, Mariet AS, et al. Comparison of the characteristics, morbidity, and mortality of COVID-19 and seasonal influenza: a nationwide, population-based retrospective cohort study. Lancet Respir Med 2021;9:251-9.

12. Letícia de Oliveira Toledo S, Sousa Nogueira L, das Graças Carvalho M, Romana Alves Rios D, de Barros Pinheiro M. COVID-19: Review and hematologic impact. Clin Chim Acta 2020;510:170-6.

13. Guzik TJ, Mohiddin SA, Dimarco A, et al. COVID-19 and the cardiovascular system: implications for risk assessment, diagnosis, and treatment options. Cardiovasc Res 2020;116:1666-87.

14. McCullough SA, Goyal P, Krishnan U, et al. Electrocardiographic Findings in Coronavirus Disease-19: Insights on Mortality and Underlying Myocardial Processes. J Card Fail 2020;26:626-32.

15. Kitkungvan $D$, Spodick $D H$. Interatrial block: is it time for more attention? J Electrocardiol 2009;42:687-92.

16. Li B, Pan Y, Li X. Type 2 Diabetes Induces Prolonged P-wave Duration without Left Atrial Enlargement. J Korean Med Sci 2016;31:525-34.

17. Acampa M, Lazzerini PE, Guideri F, Tassi R, Lo Monaco A, Martini G. Inflammation and Atrial Electrical Remodelling in Patients With Embolic Strokes of Undetermined Source. Heart Lung Circ 2019;28:917-22.

18. Broman N, Rantasärkkä K, Feuth T, et al. IL-6 and other biomarkers as predictors of severity in COVID-19. Ann Med 2021;53:410-2.

19. Commission CNH. Chinese Clinical Guidance for COVID-19 Pneumonia Diagnosis and Treatment 2020. 